\title{
The Mind and Heart of the Social Child: Developing the Empathy and Theory of Mind Scale
}

\author{
Zhenlin Wang $^{1}$ and Lamei Wang ${ }^{2}$ \\ ${ }^{1}$ Department of Psychological Studies, Hong Kong Institute of Education, 10 Lo Ping Road, Tai Po, New Territories, Hong Kong \\ ${ }^{2}$ Institute of Psychology, Chinese Academy of Sciences, 16 Lincui Road, Chaoyang District, Beijing 100101, China \\ Correspondence should be addressed to Zhenlin Wang; zlwang@ied.edu.hk
}

Received 2 July 2015; Revised 23 September 2015; Accepted 12 October 2015

Academic Editor: Andrew N. Meltzoff

Copyright (c) 2015 Z. Wang and L. Wang. This is an open access article distributed under the Creative Commons Attribution License, which permits unrestricted use, distribution, and reproduction in any medium, provided the original work is properly cited.

\begin{abstract}
Empathy and theory of mind (ToM) are distinctive psychological constructs in predicting children's social functioning. This study provided evidence of the independent nature of these constructs and developed a parent questionnaire for measuring individual differences in children's empathy and ToM. In Study 1, exploratory factor analysis and confirmatory factor analysis based on responses of 116 parents of Hong Kong children established a three-factor structure of the Empathy and Theory of Mind Scale (EToMS), that is, Empathy, Nice ToM, and Nasty ToM. An additional 189 parents of Study 2 confirmed this three-factor model. A subsample of 93 children $(M=4.97, \mathrm{SD}=.84,47$ boys $)$ from Study 2 took part in child measures of helping and lying behaviors as well as false belief understanding. The results supported the reliability and validity of the EToMS, making it a useful assessment of children's social predispositions.
\end{abstract}

\section{Introduction}

Children's social functioning is underpinned by their empathy [1] and theory of mind (ToM; [2]). While both empathy and ToM can be measured with self-reports or behavioral assessments, reports of others regarding children's social dispositions, such as parent or teacher surveys, are relatively unbiased and more cost- and time-efficient. Other-reporting is also more reliable than self-reports when studying young children due to their language constraints. The present study aimed to develop an easy-to-administer parent questionnaire on young children's empathy and ToM. Adding to the widely used child behavioral measures of these constructs (e.g., [35]), such a questionnaire would provide a tool for comprehensive assessment of children's empathy and ToM development using multiple informants and multiple methods.

\section{Empathy and Theory of Mind}

Humans are inherently social in nature. We form empathetic bond and develop social understanding in our interaction with other people. Both empathy and social understanding, the so-called theory of mind (ToM), are deeply rooted in our evolutional history and are vital for our social functioning. On the one hand, the nasty Machiavellian account $[6,7]$ proposes that in the competition for food and reproductive resources during our evolution, the "Machiavellian" strategies such as deception and manipulation ensure survival. On the other hand, the mindreading moms and cooperating babies account [8-10] promotes that compassionate empathetic bond between moms and babies is the driving force of our uniquely human communication. Moms who teach babies survival skills have to understand that babies do not know what they know; and babies learn through joint attention and imitation while interpreting moms' intentions [11]. These two accounts are not mutually exclusive. They specify the interconnected yet distinctive mechanisms that enable us to become social beings.

Empathy is the ability to perceive, understand, and react to other people's emotions appropriately $[12,13]$. It is an affective arousal similar to what the other person is feeling or would be expected to feel in a given situation [14]. In other 
words, being empathetic means that one experiences an affective state that is isomorphic to others, while being aware that the source of one's own emotional arousal is another person's affective state [15]. Empathy is the motivational factor behind prosocial behaviors, both within specific context and at the dispositions level. Those who have an empathetic disposition are more likely to be altruistic in general [14].

ToM, on the other hand, refers to the understanding of epistemic mental states such as knowledge and belief, as well as motivational mental states such as desire and emotion, and their consequences on people's behaviors [16]. A large portion of ToM research focuses on the acquisition of false belief understanding during early childhood [17]. Around 4 years of age, children begin to understand that people may have beliefs that are either not true or different from their own ones because of limited perceptual access or outdated knowledge state. This ability enables children to take other people's perspective and appropriately interpret other people's behavior according to their mental states. Recent years have witnessed a growing interest in ToM development during infancy (e.g., $[18,19]$ ) as well as middle childhood and beyond [20-24], indicating ToM is a multifaceted construct much broader than false belief understanding, and the development of ToM is an extended process.

ToM and empathy are closely related on both psychological and neuronal grounds and both undergo developmental changes throughout childhood and adolescence. Conceptually, both are "other-regarding," other perspective-taking capacities that are essential in maintaining a functional social relationship. Nevertheless, ToM concerns the understanding of the intentionality implied by propositional attitudes, such as desire and belief. Empathy, on the other hand, originates from emotional connectedness and physiological arousal and is concerned with what it feels like for another person to experience a certain emotion or sensation. This capacity develops with the emergence of self-awareness and the distinction between self and others. Arguably, the independent nature of empathy and ToM is observable in the cases of autism and psychopathy $[15,25]$.

Neurologically, empathy and ToM involve connected but different brain areas [26]. Both are associated with neurological networks that make inferences about mental states; however, empathetic response requires additional recruitment of emotional processing networks. On the one hand, sharing the emotions of others is associated with activation in neural structures that are also active while experiencing that emotion first-hand [27]. For example, areas including anterior insula (AI) and anterior cingulate cortex (ACC) are activated when participants are empathetic of other people's physical pain [28]. On the other hand, empathy is also a topdown process where executive function, contextual appraisal, and attention regulate the empathy experience [28]. Areas including the medial dorsal and orbitofrontal cortex (OFC) and the right temporoparietal junction (rTPJ) are activated in an empathy appraisal situation [29]. Interestingly, these areas are also associated with mental state understanding (e.g., $[30,31])$. When empathy and ToM stimuli are presented side by side, both ToM and empathy stimuli are associated with increased activation in networks involved in social perception, but empathy stimuli are associated with additional networks involved in emotion processing, particularly the amygdala [32]. Using event related brain potential (ERP) technique, Bowman and colleagues [33] identified selective right-posterior activation only for belief-reasoning in 7and 8-year-old children, suggesting neural specialization for ToM processing, especially belief-reasoning, is in place early during development.

ToM, as a neutral tool for social understanding, could lead to either a prosocial tendency or an antisocial tendency, depending on one's moral outlook. On the one hand, mental state understanding underpins social competency. A recent meta-analysis suggests that there is a moderate correlation between ToM and positive social interactions and popularity among peers [34]. On the other hand, ToM is an important component of employing Machiavellian strategies to tease, trick, manipulate, and outwit others [2]. The distinction between Nice ToM and Nasty ToM captures the essence of the diverse nature of the social consequences of mental state understanding depending on temperament and social goals [35]. Both Nice ToM behaviors, such as cooperating, comforting, and considering feelings of others, and Nasty ToM behaviors, such as teasing, lying, cheating, and blaming, are present as early as the preschool years. Happé and Frith [36] suggested that children with conduct disorder from troubled homes might have developed a "theory of Nasty minds." These children showed impaired social insight into cooperative situations, despite having sophisticated antisocial behaviors like lying and bullying that involve mentalizing abilities. A recent study found school-aged children who engaged in Nasty ToM behaviors demonstrated welldeveloped cognitive perspective-taking ability, while children with Nice ToM behaviors demonstrated moral and emotional sensitivity [37]. If empathy-the "hot" affective aspect of prosocial behavior, morality, altruism, and cooperation [12] — is the heart of the social child, then ToM-the "cold" cognitive aspect of interpreting other people's intentions, desires, and beliefs-is the mind of the social child.

\section{Measurements of Empathy and ToM}

Measurements of empathy range from self- and otherreports to facial, gestural, or vocal indices and physiological measures. Each of these methods has advantages and disadvantages (see [38] for a review). For example, selfreport measures, including self-report on picture-stories, questionnaires, and simulated experimental situations, are affected by social desirability, which put the measures at risk of low predictive validity when it comes to spontaneous prosocial behaviors. Another concern when using self-report measures with young children is the language requirement. For children too young to comprehend questionnaires or report accurately on picture-stories or simulated situations, other-reporting is a good alternative. Items in other-report measures are usually an adaptation of those in self-report measures. Facial and gestural responses to empathy-inducing stimulus as well as physiological measures tend to be more complicated, usually involving special equipment and time consuming data processing and analysis. Even though these 
types of data are relatively independent of social desirability, young children may react to the physiological equipment. In addition, it is difficult to single out empathic responses from other emotional or physiological reactions.

Widely used empathy other-reports include the Empathy Questionnaire (EmQue; [13]), Infant-Toddler Social and Emotional Assessment (ITSEA; [39]), and the Dispositional Positive Empathy Scale (DPES; [40]). The ITSEA has an empathy subscale, including items such as "tries to 'make up' after misbehaving," "tries to help when someone is hurt (e.g., gives a toy)," "is worried or upset when someone is hurt," and "talks about other people's feelings (like "mommy mad")." The EmQue is a more recent tool that is devoted entirely to the measurement of empathy. Based on a theoretical analysis of the empathy construct, the EmQue includes three levels of empathy: (a) contagion, (b) attention to feelings of others, and (c) prosocial actions. EmQue primarily focuses on negative empathy, that is, children's reaction to other people's negative emotions like distress, pain, and anger. The DPES further fills in the gap by adding positive empathy to the scene, focusing on children's reactions to happiness and excitement.

Unlike the diverse measures of empathy, ToM development during early childhood, on the other hand, has been primarily measured by story scenarios $[3,4]$ instead of questionnaires. The empathizing-systemizing (E-S) theory [41] proposes that understanding of (a) intentional agency and emotional response and understanding of (b) nonagentive events are two distinctive constructs, which are labeled as empathizing quotient (EQ) and systemizing quotient (SQ). However, the EQ construct includes items describing both ToM (e.g., "I can pick up quickly if someone says one thing but means another") and empathy (e.g., "I really enjoy caring for other people"). In an attempt to validate the EQ versus SQ instruments, Muncer and Ling [42] found EQ was not unifactorial. Andrew et al. [43] further suggested that instead of systemizing the opposite cognitive style to empathizing is Machiavellianism. Another tool that comes close to a ToM measure is the Strengths and Difficulties Questionnaire (SDQ; [44]). Lonigro et al. [37] factor-analyzed teachers' report on SDQ with data collected from school-aged children aged 9 to 10 and concluded that the items from the original prosocial scale in SDQ (such as "considerate of other people's feelings," "shares readily with other children," "helpful if someone is hurt, upset or feeling ill," "kind to younger children," and "often volunteers to help others") constituted a Nice ToM factor, and items from the Conduct Problems scale and Peer Problems scale (such as "often lies or cheats," "steals things at home, at school, or elsewhere," "gets on better with adults than with people of own age," and "annoys and teases other children") constituted a Nasty ToM factor.

\section{Overview of Current Study}

Although it is theoretically acknowledged that empathy and ToM are two distinctive psychological constructs contributing to children's social behavior in different ways, this claim is yet to be empirically tested, partially because the tools measuring the two constructs are independent of each other and rarely administered jointly, which makes factor analysis impossible. Considering the complexity and importance of empathy and ToM on children's social behavior, it is surprising that there is no measurement available that considers both constructs simultaneously. The present study aimed to empirically test with factor analysis the hypothesis that empathy and ToM (both nice and nasty) are distinctive constructs. In two studies, factor analyses were conducted with two samples of parents of 3- to 6-year-old children to establish and validate a 3-factor questionnaire on young children's other-regarding social predispositions. Construct validity was further examined with a nomological net illustrating the relationship among the factors and other constructs and behaviors, including child's gender, child measures of helping and lying behaviors, and false belief understanding.

\section{Study 1}

\subsection{Method}

5.1.1. Participants. Parents of 116 children from 3 to 6 years of age $\left(M_{\text {age }}=5.57 ; \mathrm{SD}=0.90,59\right.$ girls $)$ were recruited from two kindergartens and one primary school serving middle- to upper middle-class families in Hong Kong. Invitation letters and questionnaires were sent home via the children's teachers. Parents filled in the paper-and-pencil version questionnaires at home and brought them back to the teachers, who returned them to the research team. Of those who filled in the questionnaires, there were 25 fathers and 88 mothers. Less than half the parents $(43.1 \%$ for mothers and $46.6 \%$ for fathers) had completed tertiary level or above education. Over two-thirds $(68.4 \%)$ of the families had monthly income of more than HKD 20,000.

5.1.2. Measure and Procedure. In developing a new questionnaire, the strategy was to start with a reasonably large pool of items from which items with the best fit to the projected model would be selected. A new questionnaire titled the Empathy and Theory of Mind Scale (EToMS) was designed for this study with new items and those drawn from various existing measures including the Strengths and Difficulties Questionnaire (SDQ; [44]), Empathy Questionnaire (EmQue; [13]), Infant-Toddler Social and Emotional Assessment (ITSEA; [39]), Dispositional Positive Empathy Scale (DPES) [40], and the children's version of Emotion Quotient (EQ-C; [41]). The items were translated into Cantonese. A panel of five experts consisting of psychology professors and research assistants, four of whom were native Cantonese speakers, discussed and revised the items. Items were subsequently modified and amalgamated on the basis of a succession of informal trials. The final questionnaire contained 33 items. Parents were asked to rate the frequency to which their children fit the descriptions of the items on a 5point summated rating scale: 1: never, 2: rarely, 3: sometimes, 4: often, and 5: always.

5.2. Results. Measurement invariance between fathers and mothers was tested using Multigroup Confirmatory Factor Analysis and there was no significant difference $(\mu=0.19$, $p=.32$ ). Thus fathers' and mothers' reports were combined 
TABLE 1: Factor loading and communalities based on a confirmative factor analysis for 17 items $(N=116)$.

\begin{tabular}{lcc}
\hline & Nice ToM & Nasty ToM \\
\hline Enjoys stories with deceptive plots & .77 & .68 \\
Is good at taking other people's perspective into consideration & .74 & .68 \\
Can easily tell when another person wants to enter into conversation with them & .53 & .83 \\
Can easily tell when somebody is joking & .80 \\
Pretends objects are something else & .66 \\
Tells lies to get away from punishment & .62 \\
Is good at maintaining a lie when questioned about it & .61 \\
Blames others for things that they themselves have done & .51 \\
Teases, picks on, or bullies other children & .55 \\
Has stolen something they wanted from their sibling or friend & .79 \\
Likes to play practical jokes on others & .47 \\
Likes to help new children integrate in class & .54 \\
Tries to offer help when someone is hurt, upset, or feeling ill & .59 \\
Tries to stop quarrels and fights & .27 \\
When I make clear that I want some peace and quiet, my child tries not to bother me & \\
Would worry about how another child would feel if not invited to a party & \\
Shows embarrassment in socially awkward situations & \\
\hline
\end{tabular}

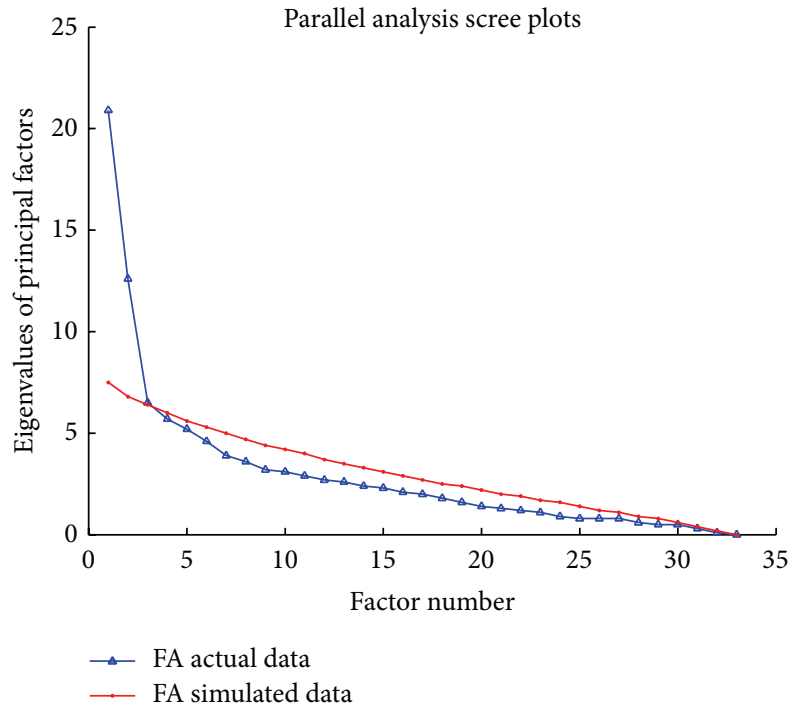

FIGURE 1: Scree plot of 33 items based on factor analysis.

in further analysis. We utilized Factor 10.3 program [45] to conduct factor analysis to identify the underlying structure of the EToMS. Scree plot based on factor analysis (Figure 1) indicated the first three eigenvalues were significantly larger than those generated from random data, suggesting three major factors. The three factors, namely, Empathy, Nice ToM, and Nasty ToM, explained $40 \%$ of the variance. During several steps, a total of 16 items were eliminated because they did not contribute to a simple factor structure with a primary factor loading $<.40$, or they had cross-loading on at least one other factor $>.30$ [46]. To check the comparative fit and interpretability of the three-factor solution, confirmative factor analysis using a structural equation modeling approach was then adopted. The data were analyzed using Mplus with weighted least squares estimation [47]. Goodness of fit was evaluated using the root mean square error of approximation (RMSEA), comparative fit index (CFI), chi-square/degrees of freedom ratio ( $\chi^{2} / \mathrm{df}$ ratio), and the Tucker-Lewis index (TLI). Acceptable model fit was defined by the following criteria: RMSEA (<.08) [48], CFI (>.90), $\chi^{2} / \mathrm{df}(<2)$, and TLI (>.90) [49]. The initial analysis generated RMSEA = $.04, \mathrm{CFI}=.96, \chi^{2} / \mathrm{df}$ ratio $=1.21$, and TLI $=.96$. The standardized factor-loading matrix for this solution with 17 items is presented in Table 1. After deleting the last item in the table which has a loading <.40 [46] and controlling covariates of children's age, gender, and family social economic status (SES, an aggregated score of the father's education level, the mother's education level, and family income level), the remaining 16 items indicate a good model fit, RMSEA $=.04$, $\mathrm{CFI}=.95, \chi^{2} / \mathrm{df}$ ratio $=1.25$, and $\mathrm{TLI}=.94$.

\section{Study 2}

The aim of Study 2 was twofold: firstly, to confirm the factor structure of the EToMS with another sample using confirmatory factor analysis; secondly, to demonstrate the construct validity of the EToMS by examining the associations between the EToMS factors and demographic variables and child measures. Particularly, prosocial white lie telling behavior should associate with the Nice ToM factor in EToMS, while strategic antisocial lie telling behavior should associate with Nasty ToM. The classic ToM measure of false belief understanding, on the other hand, should associate with Nice ToM and Nasty ToM as well as Empathy as both cognitive and affective perspective-taking are inherently related. Helping behavior should associate with the Empathy factor and the Nice ToM factor in EToMS. In addition, the study hypothesizes that child gender should correlate with the Empathy factor in EToMS. 


\subsection{Method}

6.1.1. Participants. For Study 2, 189 children from 3 to 5 years of age $\left(M_{\text {age }}=4.66\right.$; SD $=0.93,93$ girls $)$ and their parents were recruited from two middle- to upper middle-class community kindergartens in Hong Kong. Parental consent was obtained for each child. One hundred fifty mothers and 39 fathers filled in the questionnaire. Over half $(52.7 \%)$ of the families had monthly income of more than HKD 20,000, and $37.9 \%$ of both mothers and fathers had completed tertiary level or above education. A subsample of 93 children $\left(M_{\text {age }}=\right.$ $4.97, \mathrm{SD}=.84,37$ girls) took part in child measures of helping behavior, lying behavior, and false belief understanding.

6.1.2. Measures and Procedure. In addition to reporting on demographic information, including the child's age, gender, and social economic status, 189 parents also responded to the 16 -item EToMS pulled from Study 1 following the same procedure.

The subsample of 93 children participated in a behavioral study as part of a larger scale study on children's social disposition. Children's helping behavior was measured with a paradigm adapted from Zahn-Waxler et al. [5] in which an experimenter "accidently" hurting her finger over a cup of hot beverage was witnessed. The experimenter's realistic performance of being in pain lasted for one minute, during which there was no eye contact with the child. Children's empathetic reaction to the experimenter's distress was coded on a 3-point coding scheme: 0: the child did not show any verbal or behavioral reaction to the distress situation; 1 : the child showed behavioral concern to the distress situation; and 2: the child showed both behavioral and verbal concern. A white lie task measuring children's voluntary prosocial lie telling to avoid hurting other people's feelings was adapted from Talwar et al. [50] in which the child is regarded as a white lie teller if he or she tells the experimenter that he or she likes an undesirable gift from the experimenter but confesses to a parent otherwise. Responses were coded as follows: 0: the child told both the experimenter and the mother he or she liked the gift (i.e., likers); 1: the child told the experimenter he or she did not like the gift (i.e., truth tellers); or 2: the child told the experimenter he or she liked the gift but told the mother otherwise (i.e., white lie tellers). No children told the experimenter he or she liked the gift but told the mother otherwise. Children's strategic lie telling behavior was accessed with a strategic cover-up of a transgression adapted from Evans et al. [51]. Children were tempted to peek under a cup, even though they were not supposed to, while scattered particles of the cup content would be left behind as evidence of their transgression. Behaviors were coded as follows: 0: the child could not backup his or her lie (e.g., keeping silence or "I do not know"); 1: the child could provide an explanation, but the explanation was not convincing (e.g., "they walked out themselves"); or 2: the explanation was plausible (e.g., "I accidently shook the cup, and the millet came out"). In addition, two classic false belief tasks, those of unexpected contents and locations [3, 4], were adapted to measure children's false belief understanding. The order of the tasks was counterbalanced. The behavioral tasks were video-recoded and coded by two independent raters, and the average proportion agreement between raters was $82.33 \%$ (SD $=.14$ ) across tasks.

6.2. Results. Measurement invariance between fathers and mothers in Study 2 was tested using Multigroup Confirmatory Factor Analysis and there was no significant difference $(\mu=-0.23, p=.28)$. Thus fathers' and mothers' reports were combined in further analysis.

6.2.1. Confirmatory Factor Analysis. Confirmative factor analysis using a structural equation modeling approach was employed to test the model generated in Study 2 with the new sample. The data were analyzed using Mplus with weighted least squares estimation. The covariates of children's age, gender, and family SES were controlled. This analysis generated RMSEA $=.07, \mathrm{CFI}=.91, \chi^{2} / \mathrm{df}$ ratio $=2.00$, and TLI $=.89$, confirming that the 16 -item three-factor model is acceptable. All the paths from the constructs to the items were statistically significant and coefficients ranged from .40 to .85 (Table 2), suggesting that the items were good indicators of the three constructs. The findings verified the hypothesized 3-factor model.

Ordinal reliability alphas were adequate for each of the subscales: $\alpha=.71$ for Nice ToM, $\alpha=.83$ for Nasty ToM, and $\alpha$ $=.79$ for Empathy, indicating from moderate to good internal reliability. Intercorrelation between Nasty ToM and Empathy $(r=.19)$ and Nice ToM and Nasty ToM $(r=.08)$ showed relative independence between the subscales, except for that between Nice ToM and Empathy $(r=.54)$.

6.2.2. Correlates with the Behavioral Measures. Table 3 showed correlations among the EToMS factors and the child measures with descriptive data. A nomological net that defines a construct by illustrating its relation to other constructs and behaviors [52] is essential for establishing construct validity. The Empathy factor in EToMS was related to children's gender with girls being rated as more empathic than boys. The Nice ToM was significantly correlated with children's prosocial white lie telling behavior but not with other behavioral measures. Similarly, Nasty ToM was significantly correlated with strategic lie telling behavior but not with other behavioral measures. The correlations between children's helping behavior and Empathy $(r=.18$, $p=.09$ ), as well as that between helping behavior and Nice ToM $(r=.19, p=.08)$, were marginally significant, likely due to the limited variance in helping behavior. All three factors of the EToMS correlated significantly or marginally with child's false belief understanding.

\section{Discussion}

Factor analysis of the EToMS based on 2 samples verified the hypothesis that ToM and empathy were distinct psychological constructs. Furthermore, the results revealed that a 3-factor model (i.e., Empathy, Nice ToM, and Nasty ToM) fit the data. The Nice ToM factor correlated with child measure of prosocial white lie telling behavior, while the 
TABLE 2: The final questionnaire with 3-factor constructs.

\begin{tabular}{ll}
\hline & Loading \\
\hline (1) Nice theory of mind & .51 \\
Enjoys stories with deceptive plots & .59 \\
Is good at taking other people's perspective into consideration & .58 \\
Can easily tell when another person wants to enter into conversation with them & .59 \\
Can easily tell when somebody is joking & .40 \\
Pretends objects are something else & .85 \\
\hline (2) Nasty theory of mind & .56 \\
Tells lies to get away from punishment & .75 \\
Teases, picks on, or bullies other children & .51 \\
Is good at maintaining a lie when questioned about it & .42 \\
Likes to play practical jokes on others & .63 \\
Has stolen something they wanted from their sibling or friend & \\
Blames others for things that they themselves have done & .72 \\
\hline (3) Empathy & .65 \\
Likes to help new children integrate in class & .41 \\
Tries to offer help when someone is hurt, upset, or feeling ill \\
When I make clear that I want some peace and quiet, my child tries not to bother me \\
Tries to stop quarrels and fights \\
Would worry about how another child would feel if not invited to a party \\
\hline
\end{tabular}

TABLE 3: Correlations among factors and child measures with descriptive data.

\begin{tabular}{|c|c|c|c|c|c|}
\hline & Gender & $\begin{array}{c}\text { White lie } \\
.96(.76)\end{array}$ & $\begin{array}{c}\text { Strategic lie } \\
.59(.65)\end{array}$ & $\begin{array}{c}\text { Helping } \\
1.39(.75)\end{array}$ & $\begin{array}{c}\text { False belief } \\
1.54(1.13) \\
\end{array}$ \\
\hline $\begin{array}{l}\text { Nice ToM } \\
3.26(.62)\end{array}$ & -.03 & $.21^{*}$ & .18 & $.18^{\wedge}$ & $.28^{* *}$ \\
\hline $\begin{array}{l}\text { Nasty ToM } \\
2.22(.64)\end{array}$ & .01 & -.01 & $.33^{*}$ & -.01 & $.19^{\wedge}$ \\
\hline $\begin{array}{l}\text { Empathy } \\
2.92(.68)\end{array}$ & $.20^{*}$ & -.03 & .23 & $.18^{\wedge}$ & $.27^{* *}$ \\
\hline
\end{tabular}

Note. $N=93$ with systemic missing data.

Numbers within the top row and left column are means and SDs.

${ }^{*} p<.05 ;{ }^{* *} p<.01 ; \wedge p<.10$.

Nasty ToM factor correlated with the strategic antisocial lie telling behavior. The correlations between spontaneous helping behavior and the Empathy factor as well as the Nice ToM factor were marginally significant. All three factors correlated with children's false belief understanding significantly or marginally. Consistent with previous findings [14], the correlation between the Empathy factor and child's gender was significant, with girls being rated as more empathetic. Furthermore, each factor demonstrated a moderate internal consistency, and the three factors were relatively independent of each other, except for a medium-sized correlation between Nice ToM and Empathy, which can be explained by the shared prosocial valence in the two factors. The results supported the reliability and validity of the EToMS, making it a potentially useful stand-alone assessment for measuring empathy and mental state reasoning ability in young children.

The classic false belief tasks measure a neutral cognitive perspective-taking ability. However, as noted by Lonigro et al. [37] and Ronald et al. [35], real life situations involving mental state reasoning are rarely neutral. In addition to offering a useful measurement tool, the unique contribution of the current study is to empirically demonstrate the independence between Nice ToM and Nasty ToM. The two constructs formed two independent factors in EToMS. They also demonstrated different correlation patterns with either prosocial or antisocial behaviors, while both correlated with the neutral ToM measure of false belief understanding. ToM as a cognitive ability can be utilized to facilitate either prosocial or antisocial tendencies, depending on one's social predisposition.

A well-designed tool could be applied to school or community settings for assessment and intervention purpose. For example, Laghi and his colleagues [53] identified students with Nice and Nasty ToM behaviors in order to select peer models for a peer-mediated intervention for students with autism. Focusing on typically developing young children in early childhood, EToMS not only has important implications for future empirical investigations, but also could help to identify children with empathy and social understanding issues for psychoeducational intervention purpose. 


\section{Limitations}

It should be acknowledged that the sample sizes were small considering the analytical techniques applied. In addition, using parental reports has some disadvantages such that parent report contains bias and shows only modest correlation with reports from other raters [54]. However, no single source of information could be considered the gold standard and an optimal solution is to have a selection of methods such as in-person testing and multiple raters and account for rater's bias in model fitting [55]. Parents are indeed familiar with child behavior across time and situations. Parental assessment of children's social behavior is a practical option for large samples, especially young children. Although the data for validating the EToMS were obtained from parents, the items are potentially suitable for teachers to assess children's empathy and ToM. Further investigations should consider achieving EToMS reports from multiple informants including parents, teachers, social workers, and/or school psychologists to provide a versatile assessment tool of children's empathy and theory of mind development.

\section{Conflict of Interests}

The authors declare that there is no conflict of interests regarding the publication of this paper.

\section{Acknowledgment}

This study was funded by the Hong Kong University Grants Committee's General Research Fund 845211, awarded to the first author. For the other author, nothing is declared.

\section{References}

[1] N. Eisenberg and P. A. Miller, "The relation of empathy to prosocial and related behaviors," Psychological Bulletin, vol. 101, no. 1, pp. 91-119, 1987.

[2] J. W. Astington, "Sometimes necessary, never sufficient: falsebelief understanding and social competence," in Individual Differences in Theory of Mind: Implications for Typical and Atypical Development, B. Repacholi and V. Slaughter, Eds., pp. 13-38, Psychology Press, New York, NY, USA, 2003.

[3] A. Gopnik and J. W. Astington, "Children's understanding of representational change and its relation to the understanding of false belief and the appearance-reality distinction," Child Development, vol. 59, no. 1, pp. 26-37, 1988.

[4] H. Wimmer and J. Perner, "Beliefs about beliefs: representation and constraining function of wrong beliefs in young children's understanding of deception," Cognition, vol. 13, no. 1, pp. 103$128,1983$.

[5] C. Zahn-Waxler, M. Radke-Yarrow, E. Wagner, and M. Chapman, "Development of concern for others," Developmental Psychology, vol. 28, no. 1, pp. 126-136, 1992.

[6] R. W. Byrne and A. Whiten, Eds., Machiavellian Intelligence II: Extensions and Evaluations, Cambridge University Press, Cambridge, UK, 1997.

[7] P. Richerson, R. Boyd, and J. Henrich, "Cultural evolution of human cooperation," in Genetic and Cultural Evolution of
Cooperation, P. Hammerstein, Ed., pp. 357-388, MIT Press, Cambridge, Mass, USA, 2003.

[8] R. Brockway, "Evolving to be mentalists: the 'mind-reading mums' hypothesis," in From Mating to Mentality: Evaluating Evolutionary Psychology, K. Sterelny and J. Fitness, Eds., pp. 95123, Psychology Press, New York, NY, USA, 2003.

[9] A. N. Meltzoff, “Like me': a foundation for social cognition," Developmental Science, vol. 10, no. 1, pp. 126-134, 2007.

[10] M. Tomasello, Origins of Human Communication, The MIT Press, Cambridge, Mass, USA, 2008.

[11] J. Decety and A. N. Meltzoff, "Empathy, imitation, and the social brain," in Empathy: Philosophical and Psychological Perspectives, A. Copland and P. Goldie, Eds., pp. 58-81, Oxford University Press, New York, NY, USA, 2011.

[12] M. L. Hoffman, Empathy and Moral Development: Implications for Caring and Justice, Cambridge University Press, New York, NY, USA, 2000.

[13] C. Rieffe, L. Ketelaar, and C. H. Wiefferink, "Assessing empathy in young children: construction and validation of an Empathy Questionnaire (EmQue)," Personality and Individual Differences, vol. 49, no. 5, pp. 362-367, 2010.

[14] N. Eisenberg, R. A. Fabes, and T. L. Spinrad, "Prosocial behavior," in Handbook of Child Psychology: Vol. 3. Social, Emotional, and Personality Development, W. Damon, R. M. Lerner, and N. Eisenberg, Eds., pp. 646-718, Wiley, New York, NY, USA, 6th edition, 2006.

[15] T. Singer, "Understanding others: brain mechanisms of theory of mind and empathy," in Neuroeconomics: Decision Making and the Brain, P. W. Glimcher, C. F. Camerer, E. Fehr, and R. A. Poldracj, Eds., pp. 251-268, Elsevier Academic Press, San Diego, Calif, USA, 2009.

[16] J. Perner, Understanding the Representational Mind, MIT Press, Cambridge, Mass, USA, 1991.

[17] H. M. Wellman, D. Cross, and J. Watson, "Meta-analysis of theory-of-mind development: the truth about false belief," Child Development, vol. 72, no. 3, pp. 655-684, 2001.

[18] K. K. Oniski and R. Baillargeon, "Do 15-month-old infants understand false beliefs?" Science, vol. 308, no. 5719, pp. 255258, 2005.

[19] B. Sodian, "Theory of mind in infancy," Child Development Perspectives, vol. 5, no. 1, pp. 39-43, 2011.

[20] R. Banerjee, D. Watling, and M. Caputi, "Peer relations and the understanding of faux pas: longitudinal evidence for bidirectional associations," Child Development, vol. 82, no. 6, pp. 18871905, 2011.

[21] R. T. Devine and C. Hughes, "Silent films and strange stories: theory of mind, gender, and social experiences in middle childhood," Child Development, vol. 84, no. 3, pp. 989-1003, 2013.

[22] D. Dodell-Feder, S. H. Lincoln, J. P. Coulson, and C. I. Hooker, "Using fiction to assess mental state understanding: a new task for assessing theory of mind in adults," PLOS ONE, vol. 8, no. 11, Article ID e81279, 2013.

[23] F. J. Ferguson and E. J. Austin, "Associations of trait and ability emotional intelligence with performance on Theory of Mind tasks in an adult sample," Personality and Individual Differences, vol. 49, no. 5, pp. 414-418, 2010.

[24] Z. Wang, R. T. Devine, K. K. Wong, and C. Hughes, "Theory of mind and executive function in middle childhood across cultures," Journal of Experimental Child Psychology, In press. 
[25] R. J. R. Blair, "Responding to the emotions of others: dissociating forms of empathy through the study of typical and psychiatric populations," Consciousness and Cognition, vol. 14, no. 4, pp. 698-718, 2005.

[26] R. L. E. P. Reniers, B. A. Völlm, R. Elliott, and R. Corcoran, "Empathy, ToM, and self-other differentiation: an fMRI study of internal states," Social Neuroscience, vol. 9, no. 1, pp. 50-62, 2014.

[27] S. D. Preston and F. B. M. de Waal, "Empathy: its ultimate and proximate bases," Behavioral and Brain Sciences, vol. 25, no. 1, pp. 1-20, 2002.

[28] T. Singer and C. Lamm, "The social neuroscience of empathy," Annals of the New York Academy of Sciences, vol. 1156, no. 1, pp. 81-96, 2009.

[29] C. Lamm, H. C. Nausbaum, A. N. Meltzoff, and J. Decety, "What are you feeling? Using functional magnetic resonance imaging to assess the modulation of sensory and affective responses during empathy for pain," PLoS ONE, vol. 2, no. 12, Article ID e1292, 2007.

[30] R. Saxe and A. Wexler, "Making sense of another mind: the role of the right temporo-parietal junction," Neuropsychologia, vol. 43, no. 10, pp. 1391-1399, 2005.

[31] T. Singer, "The neuronal basis and ontogeny of empathy and mind reading: review of literature and implications for future research," Neuroscience and Biobehavioral Reviews, vol. 30, no. 6, pp. 855-863, 2006.

[32] B. A. Völlm, A. N. W. Taylor, P. Richardson et al., "Neuronal correlates of theory of mind and empathy: a functional magnetic resonance imaging study in a nonverbal task," NeuroImage, vol. 29, no. 1, pp. 90-98, 2006.

[33] L. C. Bowman, D. Liu, A. N. Meltzoff, and H. M. Wellman, "Neural correlates of belief- and desire-reasoning in 7- and 8year-old children: an event-related potential study," Developmental Science, vol. 15, no. 5, pp. 618-632, 2012.

[34] V. Slaughter, K. Imuta, C. Peterson, and J. Henry, "Meta-analysis of theory of mind and peer popularity in the preschool and early school years," Child Development, vol. 86, no. 4, pp. 1159-1174, 2014.

[35] A. Ronald, F. Happé, C. Hughes, and R. Plomin, "Nice and nasty theory of mind in preschool children: nature and nurture," Social Development, vol. 14, no. 4, pp. 664-684, 2005.

[36] F. Happé and U. Frith, "Theory of mind and social impairment in children with conduct disorder," British Journal of Developmental Psychology, vol. 14, no. 4, pp. 385-398, 1996.

[37] A. Lonigro, F. Laghi, R. Baiocco, and E. Baumgartner, "Mind reading skills and empathy: evidence for nice and nasty ToM behaviours in school-aged children," Journal of Child and Family Studies, vol. 23, no. 3, pp. 581-590, 2014.

[38] Q. Zhou, C. Valiente, and N. Eisenberg, "Empathy and its measurement," in Positive Psychological Assessment: A Handbook of Models and Measures, S. J. Lopez and C. R. Snyder, Eds., pp. 269-284, American Psychological Association, Washington, DC, USA, 2003.

[39] A. S. Carter, M. J. Briggs-Gowan, S. M. Jones, and T. D. Little, "The Infant-Toddler Social and Emotional Assessment (ITSEA): factor structure, reliability, and validity," Journal of Abnormal Child Psychology, vol. 31, no. 5, pp. 495-514, 2003.

[40] J. Sallquist, N. Eisenberg, T. L. Spinrad, N. D. Eggum, and B. M. Gaertner, "Assessment of preschoolers' positive empathy: concurrent and longitudinal relations with positive emotion, social competence, and sympathy," Journal of Positive Psychology, vol. 4, no. 3, pp. 223-233, 2009.
[41] B. Auyeung, S. Wheelwright, C. Allison, M. Atkinson, N. Samarawickrema, and S. Baron-Cohen, "The children's empathy quotient and systemizing quotient: sex differences in typical development and in autism spectrum conditions," Journal of Autism and Developmental Disorders, vol. 39, no. 11, pp. 1509-1521, 2009.

[42] S. J. Muncer and J. Ling, "Psychometric analysis of the empathy quotient (EQ) scale," Personality and Individual Differences, vol. 40, no. 6, pp. 1111-1119, 2006.

[43] J. Andrew, M. Cooke, and S. J. Muncer, "The relationship between empathy and Machiavellianism: an alternative to empathizing-systemizing theory," Personality and Individual Differences, vol. 44, no. 5, pp. 1203-1211, 2008.

[44] R. Goodman, "The strengths and difficulties questionnaire: a research note," Journal of Child Psychology and Psychiatry and Allied Disciplines, vol. 38, no. 5, pp. 581-586, 1997.

[45] U. Lorenzo-Seva and P. J. Ferrando, "FACTOR 9.2: a comprehensive program for fitting exploratory and semiconfirmatory factor analysis and IRT models," Applied Psychological Measurement, vol. 37, no. 6, pp. 497-498, 2013.

[46] N. K. Bowen and S. Guo, Structural Equation Modeling, Oxford University Press, New York, NY, USA, 2011.

[47] L. K. Muthen and B. O. Muthen, The Comprehensive Modelling Program for Applied Researchers: User's Guide, 5, Mplus, 2012.

[48] R. C. MacCallum, M. W. Browne, and H. M. Sugawara, "Power analysis and determination of sample size for covariance structure modeling," Psychological Methods, vol. 1, no. 2, pp. 130-149, 1996.

[49] K. A. Bollen and J. S. Long, "Tests for structural equation models," Sociological Methods \& Research, vol. 21, no. 2, pp. 123-131, 1992.

[50] V. Talwar, S. M. Murphy, and K. Lee, "White lie-telling in children for politeness purposes," International Journal of Behavioral Development, vol. 31, no. 1, pp. 1-11, 2007.

[51] A. D. Evans, F. Xu, and K. Lee, "When all signs point to you: lies told in the face of evidence," Developmental Psychology, vol. 47, no. 1, pp. 39-49, 2011.

[52] L. J. Cronbach and P. E. Meehl, "Construct validity in psychological tests," Psychological Bulletin, vol. 52, no. 4, pp. 281-302, 1955.

[53] F. Laghi, A. Lonigro, S. Levanto, M. Ferraro, E. Baumgartner, and R. Baiocco, "The role of nice and nasty theory of mind in teacher-selected peer models for adolescents with autism spectrum disorders," Measurement and Evaluation in Counseling and Development, 2015.

[54] J. M. Najman, G. M. Williams, J. Nikles et al., "Bias influencing maternal reports of child behaviour and emotional state," Social Psychiatry and Psychiatric Epidemiology, vol. 36, no. 4, pp. 186194, 2001.

[55] J. K. Hewitt, J. L. Silberg, M. C. Neale, L. J. Eaves, and M. Erickson, “The analysis of parental ratings of children's behavior using LISREL," Behavior Genetics, vol. 22, no. 3, pp. 293-317, 1992. 

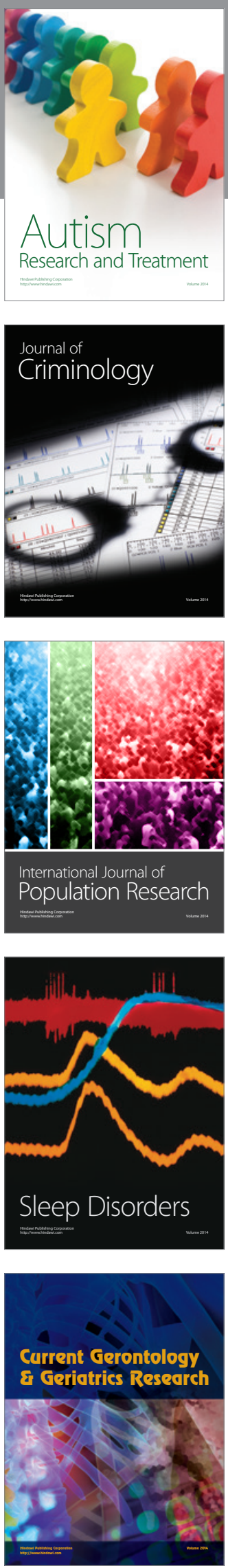
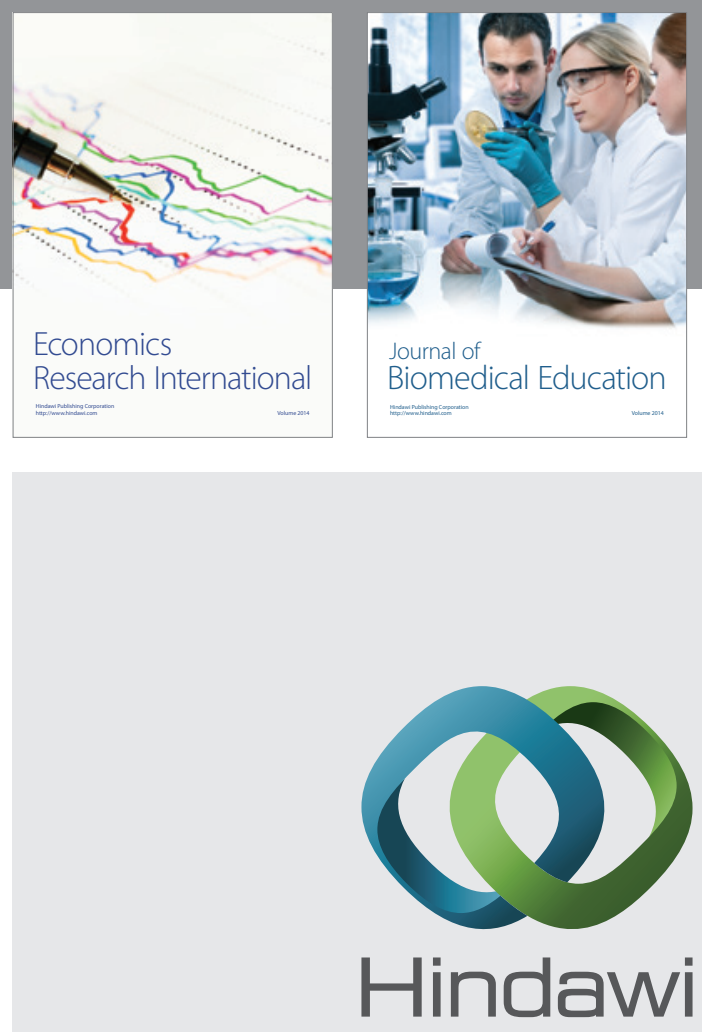

Submit your manuscripts at

http://www.hindawi.com
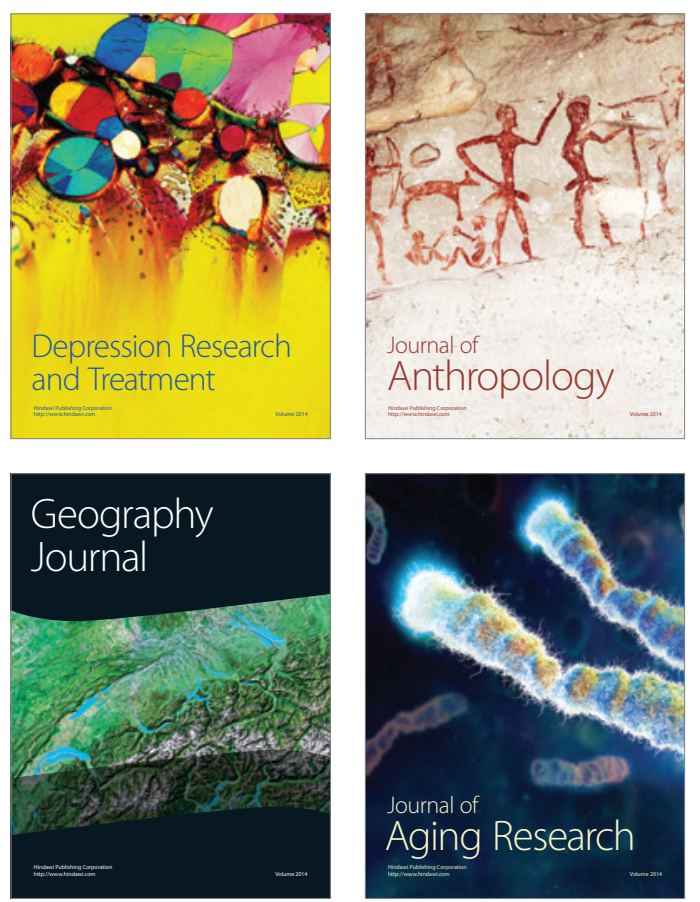
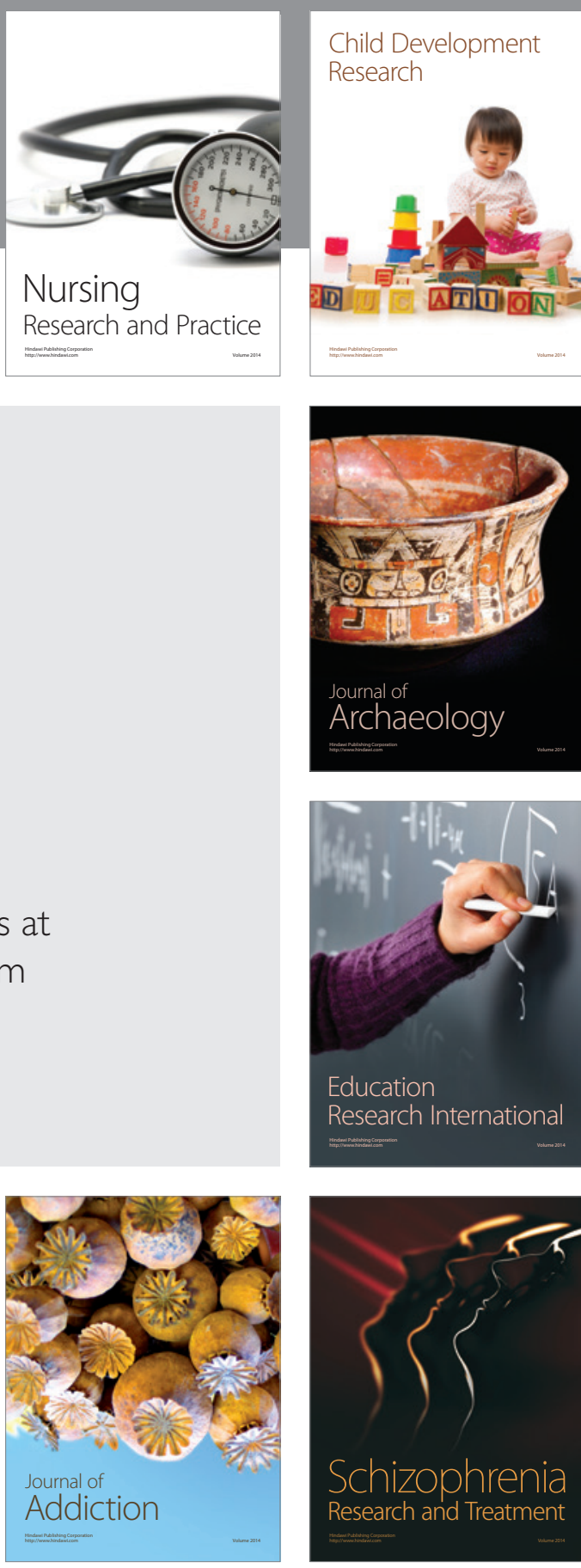

(D)
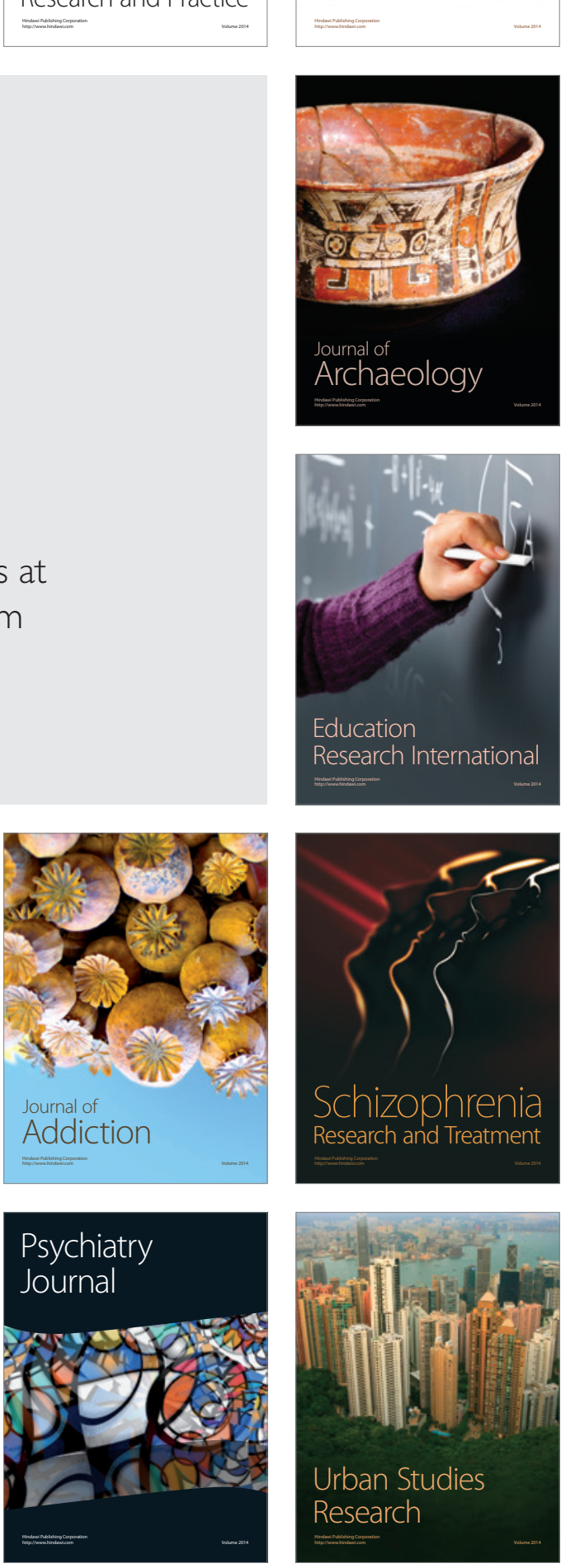